\title{
Chemical and structural effects on ionic conductivity at columnar grain boundaries in yttria-stabilized zirconia thin films
} \author{
Osamu SAKURAI** and Kazuo SHINOZAKI** \\ Institute for Materials Research, Tohoku University, Sendai 980-8577, Japan \\ ${ }^{*}$ Interdisciplinary Graduate School of Science and Engineering, \\ 4259 Nagatsuta-cho, Midori-ku, Yokohama 226-8503, Japan \\ ${ }^{* *}$ Graduate School of Science and Engineering, Tokyo Institute of Technology, \\ 2-12-1 0-okayama, Meguro-ku, Tokyo 152-8550, Japan
}

Takanori KIGUCHI, ${ }^{\dagger}$ Yumiko KODAMA, Toyohiko J. KONNO, Hiroshi FUNAKUBO, ${ }^{*}$

This study elucidated the effects of coherence and chemical composition on ionic conductivity at columnar grain boundaries of $6 \mathrm{~mol} \% \mathrm{Y}_{2} \mathrm{O}_{3}$ doped $\mathrm{ZrO}_{2}$ (YSZ) thin films. The YSZ thin films were deposited with several orientation textures on MgO (100), $\mathrm{Al}_{2} \mathrm{O}_{3}$ (102), and $\mathrm{SiO}_{2}$-glass substrates using metal-organic chemical vapor deposition (MOCVD). Impedance measurements revealed the total ionic conductivity of the thin films. The activation energy of the ionic conduction of YSZ thin films on MgO or $\mathrm{Al}_{2} \mathrm{O}_{3}$ substrates was $90-120 \mathrm{~kJ} / \mathrm{mol}$. These films showed similar dependence that simply increased along with decreasing coherency at the columnar grain boundaries. However, that of YSZ thin films on $\mathrm{SiO}_{2}$ glass substrate showed dependence of the coherency at the columnar grain boundaries, but the value is higher than those of the films on $\mathrm{MgO}$ or $\mathrm{Al}_{2} \mathrm{O}_{3}$ substrates by more than $20 \mathrm{~kJ} / \mathrm{mol}$. Structural and compositional analyses clarified that the second phase of $\mathrm{SiO}_{2}$ is segregated at mid-gaps between columnar grain boundaries in YSZ thin films on a $\mathrm{SiO}_{2}$ glass substrate. Results show that two factors affect ionic conductivity at the columnar grain boundaries in YSZ thin films: structural coherency and the second phase of ionic insulator.

(2014 The Ceramic Society of Japan. All rights reserved.

Key-words : Zirconia, Columnar structure, Grain boundary, Coherency, $\mathrm{SiO}_{2}$, lonic conduction, Thin film, TEM, HAADF-STEM

[Received December 18, 2013; Accepted February 10, 2014]

\section{Introduction}

Stabilized $\mathrm{ZrO}_{2}$ doped with rare earth sesqui-oxides $\left(\mathrm{R}_{2} \mathrm{O}_{3}\right.$ : $\mathrm{R}=\mathrm{Sc}, \mathrm{Y}, \mathrm{Yb}$ etc.) are well known to show excellent oxygen ionic conductivity at an elevated temperature. ${ }^{1)-10)}$ This property is attractive for oxygen sensors and electrolytes for use in solidoxide fuel cells (SOFCs). Most early studies of the ionic conductivity on $\mathrm{Y}_{2} \mathrm{O}_{3}$ doped $\mathrm{ZrO}_{2}$ (YSZ) have investigated bulk crystals. ${ }^{11), 12)}$ Typical operating temperatures of YSZ electrolytes generally require temperatures higher than $700^{\circ} \mathrm{C}$. For energy conservation, it is important to lower the operating temperature. Decreasing the ohmic loss across the electrolyte can lower the operation temperature of SOFCs and its life cycle. Therefore, thin film electrolytes are attractive for use as next-generation electrolytes operating at lower temperatures. ${ }^{13), 14)}$

It is well known that the microstructures of thin films affect on the ionic conductivity of YSZ. The oxide thin films particularly tend to have a characteristic columnar structure because of the larger lattice mismatch between a thin film and a substrate. The large lattice mismatch engenders 3D island growth of the films, which leads to a columnar morphology with high density of grain boundaries and dislocations. Among the early reports of studies of YSZ, there is contradictions on the role of grain boundaries. Aoki et al. showed that the grain boundary acts as a barrier against the conduction of oxygen ions for polycrystalline YSZ. ${ }^{15)}$ Kosacki et al. reported that the grain boundary in nanocrystalline YSZ acts

\footnotetext{
${ }^{\dagger}$ Corresponding author: T. Kiguchi; E-mail: tkiguchi@imr.tohoku. ac.jp

* Preface for this article: Dol http://dx.doi.org/10.2109/jcersj2.122.P6-1
}

as a rapid diffusion path of oxygen ions. ${ }^{16)}$ Otsuka et al. described that the impurity segregation along grain boundaries also affects the YSZ properties. ${ }^{17), 18)}$ Most studies of the grain boundaries of YSZ thin films have examined polycrystalline films with random orientation. Few researchers have reported examinations of the ionic conductivity of epitaxial YSZ thin films ${ }^{19)}$ and the columnar grain boundary structure of YSZ thin films. ${ }^{20)}$

An earlier report described the effects of the coherence of the columnar grain boundary on ionic conductivity. ${ }^{21)}$ Complex impedance measurements of $6 \mathrm{~mol} \% \mathrm{Y}_{2} \mathrm{O}_{3}$ doped $\mathrm{ZrO}_{2}$ (6YSZ) thin films were conducted with the columnar and nanocrystalline morphology with coherence of various sorts at the boundary. The ionic conductivity and the apparent activation energy of the migration of oxygen ions decreases and increases dependent on the tilt and rotation angle from the coherent grain boundary. No impurity was detected at these boundaries using an energy dispersive X-ray spectroscopy (EDS) equipped with a transmission electron microscopy (TEM).

Our recent study revealed an effect of chemical composition at the columnar grain boundary on the ionic conductivity 6YSZ/ $\mathrm{SiO}_{2}$ thin films compared with coherent $6 \mathrm{YSZ} / \mathrm{MgO}$ and 6YSZ/ $\mathrm{Al}_{2} \mathrm{O}_{3}$ thin films. The second phase of ionic insulator increases the apparent activation energy of ionic conduction at the columnar grain boundary. This study was undertaken to elucidate the effects of the chemical and the coherent effect at the columnar grain boundary on the ionic and compositional viewpoints.

\section{Experimental procedures}

Metal-organic chemical vapor deposition (MOCVD) with the vertical cold-wall-type reactor was used to prepae $\mathrm{Y}_{2} \mathrm{O}_{3}$-doped 
$\mathrm{ZrO}_{2}$ thin films. Films were prepared at $500-600^{\circ} \mathrm{C}$ on $\mathrm{MgO}$ (100), $\mathrm{Al}_{2} \mathrm{O}_{3}$ (102), and $\mathrm{SiO}_{2}$ glass substrates from $\mathrm{Zr}\left(\mathrm{O} \cdot \mathrm{t}-\mathrm{C}_{4} \mathrm{H}_{9}\right)_{4}$ - $\mathrm{Y}\left(\mathrm{C}_{11} \mathrm{H}_{19} \mathrm{O}_{2}\right)_{3}-\mathrm{O}_{2}$ system. Details of the thin film deposition were presented in an earlier report. ${ }^{22)}$ The average $\mathrm{Y}_{2} \mathrm{O}_{3}$ concentrations in YSZ thin films were measured using energy dispersive X-ray spectroscopy (EDX, DX95; EDAX Inc.). Films of $6 \mathrm{~mol} \% \mathrm{Y}_{2} \mathrm{O}_{3}$ concentration were selected for examination in this study. Only $6 \mathrm{YSZ}$ shows various orientation degrees on $\mathrm{MgO}, \mathrm{Al}_{2} \mathrm{O}_{3}$, and $\mathrm{SiO}_{2}$ glass substrates. Then, $6 \mathrm{YSZ}$ was selected for this study to fix the $\mathrm{Y}_{2} \mathrm{O}_{3}$ composition. Herein, $6 \mathrm{YSZ}$ is abbreviated to YSZ. Impedance spectroscopy of YSZ thin films was conducted using an impedance analyzer (4192A; Agilent Corp.) at temperatures of $600-900^{\circ} \mathrm{C}$ in an electrical furnace in air. Details of the impedance spectroscopy were described in a separate paper. ${ }^{21)}$ A two-probe technique was used for measurement of the impedance spectra because of the adequately high impedance of YSZ. Pt wires were attached with Pt paste to the bilateral terminal of the samples and were sintered at $800^{\circ} \mathrm{C}$ in air. The frequency range of measurements was $10 \mathrm{MHz}$ to $10 \mathrm{~Hz}$. The impedance and the ionic conductivity of the films were obtained from the fitting of measured impedance spectra (Nyquist plots). The activation energy of the conduction was obtained from the slope of the Arrhenius plot $\log (\sigma \mathrm{T})$ versus $1 / \mathrm{T}$, where $\sigma$ represents ionic conductivity.

The phase and orientation of the prepared films were measured using XRD (X'-pert-MPD PW3050; Philips Co.) and an X-ray pole figure (X'-pert-OEC PW3050; Philips Co.), using $\mathrm{Cu}-\mathrm{K} \alpha$ line operating at $40 \mathrm{kV}$ and $40 \mathrm{~mA}$. The X-ray pole figures of 100 poles of YSZ with [101] projection were measured. To evaluate the degree of orientation, the average full width at half maximum of 100 poles, the $W$-factor, was calculated. Shown in Fig. 1(a), the $W$-factor is defined as presented below. ${ }^{21)}$

$$
\mathrm{W}=\left(W_{\phi} \cdot W_{\varphi}\right)^{\frac{1}{2}}
$$

Therein, $W_{\phi}$ and $W_{\varphi}$ respectively represent the FWHM along an azimuth angle $\phi$ and an elevation angle $\varphi$ directions of the pole figure. $W_{\phi}$ and $W_{\varphi}$ respectively denote the orientation degrees of normal and along the substrates. The orientation degree of

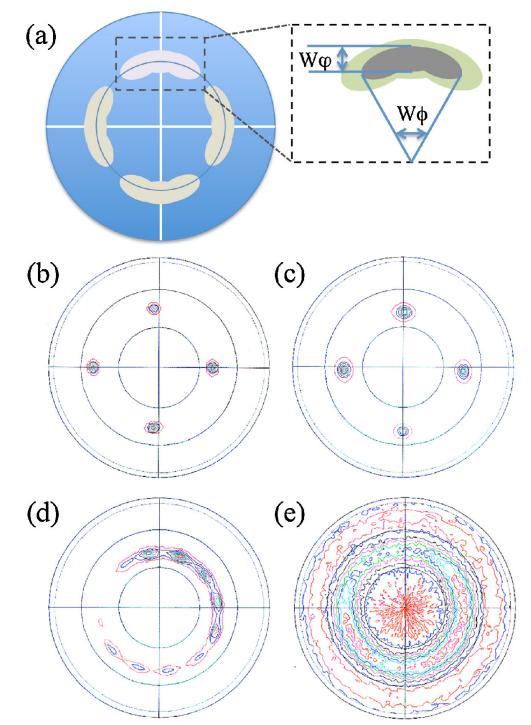

Fig. 1. (a) Schematic definition of the $W$-factor, the average FWHM of (100) pole with [101] projection, ${ }^{21)}$ and X-ray pole figures about the (100) pole with [101] projection of YSZ thin films with different substrates and deposition temperatures: (b) $600^{\circ} \mathrm{C}(\mathrm{MgO}),{ }^{21)}$ (b) $\left.600^{\circ} \mathrm{C}\left(\mathrm{Al}_{2} \mathrm{O}_{3}\right),{ }^{21}\right)$ (d) $500^{\circ} \mathrm{C}\left(\mathrm{Al}_{2} \mathrm{O}_{3}\right),{ }^{21)}$ and (e) $600^{\circ} \mathrm{C}\left(\mathrm{SiO}_{2}\right)$.
(200) plane was estimated using this factor. Values of $W_{\phi}$ and $W_{\varphi}$ are the averages of the four 100 poles in the epitaxial films [Figs. 1(b) and 1(c)]. They are $1 / 4$ the value of the total $W$-factor in the uniaxial films [Figs. 1(d) and 1(e)] corresponding to the equivalent FWHM of 100 pole. The value of $90^{\circ}$ stands for completely random orientation of grains.

Cross-sectional observation of YSZ thin films was conducted using high-resolution transmission electron microscopy (HRTEM, JEM-2010; JEOL Ltd.) and an aberration-corrected high-angle annular dark field-scanning transmission electron microscope (HAADF-STEM, JEM-ARM200F; JEOL Ltd.) operating at $200 \mathrm{kV}$. STEM-EDS spectrum imaging was conducted using $\mathrm{Mg}-\mathrm{K}, \mathrm{Al}-\mathrm{K}, \mathrm{Si}-\mathrm{K}, \mathrm{Zr}-\mathrm{K}$, and $\mathrm{Y}-\mathrm{K}$ lines. Thin foils of YSZ thin films were prepared using one of two methods: (1) conventional mechanical polishing and ion milling method using dimple polishing (Dimple Grinder Model656; Gatan Inc.) and Ar ion milling (Dual Mill Model600, PIPS Model 691; Gatan Inc.); (2) focused ion beam (FIB) micro-sampling (Quanta 200 3D, FEI Co.), followed by low-energy Ar ion milling at $0.3 \mathrm{kV}$ (Gentle Mill Ion Miller Model IV5; Technoor-Linda Scientific Technical Development Ltd. Co.) to remove the damage layer introduced during FIB micro-sampling.

\section{Results}

\subsection{Quantifying the degree of orientation of YSZ films}

The orientation of the YSZ thin films was evaluated using the $W$-factor obtained from the X-ray pole figure. Figure 1 shows (100) pole figures of typical YSZ thin films with [101] projection. The orientation degree was controlled by varying the substrate species and the deposition temperatures as follows: (a) $\mathrm{MgO}$ substrate at $600^{\circ} \mathrm{C},{ }^{21)}$ (b) $\mathrm{Al}_{2} \mathrm{O}_{3}$ substrate at $600^{\circ} \mathrm{C}$, ${ }^{21)}$ (c) $\mathrm{Al}_{2} \mathrm{O}_{3}$ substrate at $500^{\circ} \mathrm{C}^{21)}$ and (d) $\mathrm{SiO}_{2}$ glass substrate at $600^{\circ} \mathrm{C}$. The data in Figs. 1(a)-1(c) were quoted from an earlier report. ${ }^{21)}$ The respective $W$-factors in Fig. 1 are (a) $4.2^{\circ}$, (b) $6.8^{\circ}$, (c) $20.3^{\circ}$, and (d) $38.2^{\circ}$. The order of orientation degree is $\mathrm{YSZ} / \mathrm{MgO}>\mathrm{YSZ} /$ $\mathrm{Al}_{2} \mathrm{O}_{3}>\mathrm{YSZ} / \mathrm{SiO}_{2}$ under equal deposition temperatures. The orientation degree is larger, with higher deposition temperatures of films on the $\mathrm{Al}_{2} \mathrm{O}_{3}$ substrate. Consequently, the YSZ thin film on $\mathrm{MgO}$ and $\mathrm{Al}_{2} \mathrm{O}_{3}$ substrate deposited at $600^{\circ} \mathrm{C}$ has epitaxial like orientation. Those on $\mathrm{Al}_{2} \mathrm{O}_{3}$ substrate at $500^{\circ} \mathrm{C}$ and $\mathrm{SiO}_{2}$ glass substrate respectively show strong and weak uniaxial orientation. Details of the film morphology are presented in the section 3.3 .

\subsection{Ionic conductivity of YSZ thin films}

Impedance spectra of each YSZ films were measured to evaluate the ionic conductivity and apparent activation energy. Figure 2 shows typical impedance spectra measured at $700^{\circ} \mathrm{C}$ of thin films on $\mathrm{MgO}, \mathrm{Al}_{2} \mathrm{O}_{3}$, and $\mathrm{SiO}_{2}$ glass substrates with different $W$-factors of $4.2,6.8$, and $38.2^{\circ}$, respectively. The thin films with smaller $W$-value simply have smaller impedance. One semi-circle was measured for all $W$-values.

The real part and the imaginary part of the impedance were calculated by assuming an equivalent circuit of a parallel connection of a resistance and a capacitance component, Fig. 3 depicts Arrhenius-type plots of the product of ionic conductivity $\sigma$ and temperature $\mathrm{T}$ for each $\mathrm{W}$-factor obtained from the measured impedance spectra to calculate the apparent activation energy for the grain boundary conduction. Figure 3 depicts that all films show linearity and no inflection of the plot for measured temperatures. Among them, $\mathrm{YSZ} / \mathrm{MgO}$ and $\mathrm{YSZ} / \mathrm{Al}_{2} \mathrm{O}_{3}$ show conductivity characteristics that are mutually close, ${ }^{21)}$ on the 


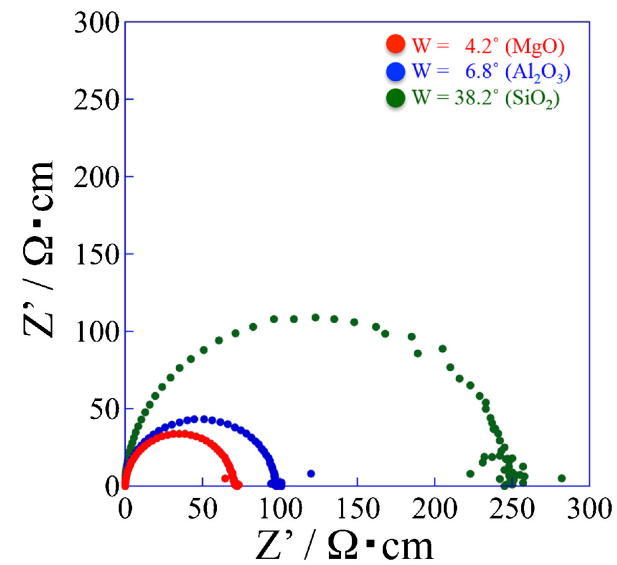

Fig. 2. Impedance plot of YSZ thin films with different orientation degrees: (a) $W=4.2^{\circ}$, (b) $W=6.8^{\circ}$, and (c) $W=38.2^{\circ}$. The measurement temperature is $700^{\circ} \mathrm{C}$.

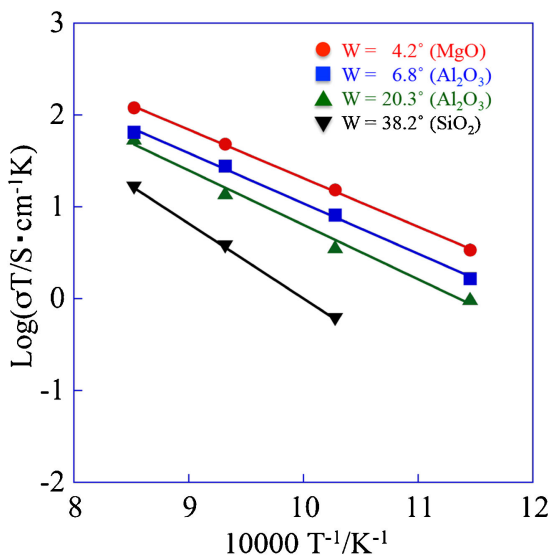

Fig. 3. Typical Arhenius-type plot in the temperatures of $600-900^{\circ} \mathrm{C}$ of the films with $W=4.2^{\circ}(\mathrm{MgO}),,^{21)} 6.8^{\circ}\left(\mathrm{Al}_{2} \mathrm{O}_{3}\right),{ }^{21)} 20.3^{\circ}\left(\mathrm{Al}_{2} \mathrm{O}_{3}\right),{ }^{21)}$ and $38.2^{\circ}\left(\mathrm{SiO}_{2}\right)$.

other hand, $\mathrm{YSZ} / \mathrm{SiO}_{2}$ shows lower conductivity. The $\mathrm{YSZ}$ thin film with $W=4.2^{\circ}$ respectively shows $2,3,8-22$ times higher ionic conductivity than that with $W=6.8^{\circ}, W=20.3^{\circ}$, and $W=38.2^{\circ}$. These results demonstrate that the grain boundary acts as a conduction depending on the W-value. Particularly, the conductivity of $\mathrm{YSZ} / \mathrm{SiO}_{2}$ film with $W=38.2^{\circ}$ shows greater temperature dependence.

Based on these analyses, the logarithm of the ionic conductivity and the apparent activation energy for all YSZ thin films measured in this study are inferred, respectively, as shown in Figs. 4 and $\mathbf{5}$. In Fig. 4, two trends of dependence of ionic conductivity on the $W$-factor are apparent: one is that of $\mathrm{YSZ} / \mathrm{MgO}$ and $\mathrm{YSZ} / \mathrm{Al}_{2} \mathrm{O}_{3}$ thin films (solid circles, squares, and triangles with solid lines); ${ }^{21}$ ) the other is that of $\mathrm{YSZ} / \mathrm{SiO}_{2}$ thin films (open circles, squares, and triangles with dotted lines). The logarithm of the ionic conductivity of all films decreases with the W-factor, as reported from a previous study. ${ }^{21)}$ This behavior is valid for all measurement temperatures of $600-900^{\circ} \mathrm{C}$. This result demonstrates that the ionic conductivity of oxygen ions is sensitive to the coherence of columnar grain boundaries. However, $\mathrm{YSZ} / \mathrm{SiO}_{2}$ thin films show the different dependence of ionic conductivity on the $W$ factor.

Figure 5 shows that the apparent activation energy is sensitive to the coherence of columnar grain boundaries. The activation energy of $\mathrm{YSZ} / \mathrm{SiO}_{2}$ thin films also appears to be greater than

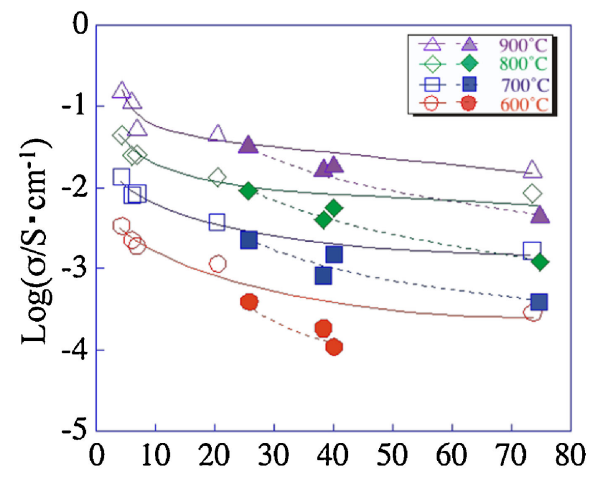

Average FWHM of 100 pole (W-factor) / Deg

Fig. 4. Dependence of the $W$-factor of the films on the ionic conductivity across the columnar grain boundary. Open circles, squares, and triangles with solid lines correspond to $\mathrm{YSZ} / \mathrm{MgO}$ and $\mathrm{YSZ} / \mathrm{Al}_{2} \mathrm{O}_{3}$ thin films. ${ }^{21)}$ Filled circles, squares, and triangles with solid lines correspond to $\mathrm{YSZ} / \mathrm{SiO}_{2}$ thin films.

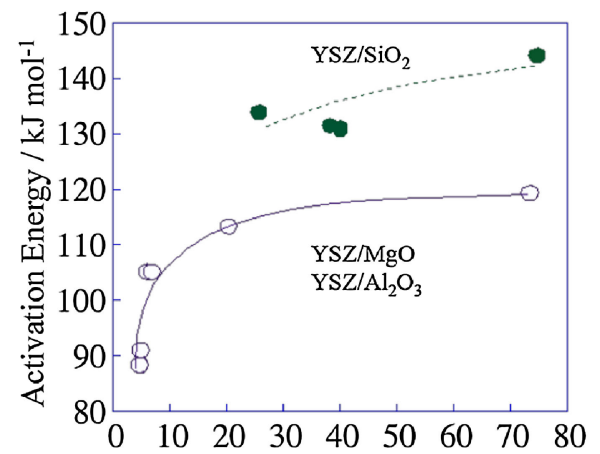

Average FWHM of 100 pole (W-factor) / Deg

Fig. 5. Dependence of the $W$-factor of the films on the apparent activation energy for the ionic conductivity across the columnar grain boundary. Open circles, squares, and triangles with solid lines correspond to $\mathrm{YSZ} / \mathrm{MgO}$ and $\mathrm{YSZ} / \mathrm{Al}_{2} \mathrm{O}_{3}$ thin films. ${ }^{21)}$ Filled circles, squares, and triangles with solid lines correspond to $\mathrm{YSZ} / \mathrm{SiO}_{2}$ thin films.

those of $\mathrm{YSZ} / \mathrm{MgO}$ or $\mathrm{Al}_{2} \mathrm{O}_{3}$ thin films by $20 \mathrm{~kJ} / \mathrm{mol}$, independent of a $W$-value larger than $25^{\circ}$. Apart from this point, all films show similar $W$-factor dependence. The highest coherence YSZ/ $\mathrm{MgO}$ thin film with $W=4.2^{\circ}$ shows apparent activation energy close to $90 \mathrm{~kJ} / \mathrm{mol}$. The medium coherence $\mathrm{YSZ} / \mathrm{Al}_{2} \mathrm{O}_{3}$ thin film with $W=6.8^{\circ}$ shows $103 \mathrm{~kJ} / \mathrm{mol}$. YSZ $/ \mathrm{Al}_{2} \mathrm{O}_{3}$ thin films with larger $W$ values show $110-120 \mathrm{~kJ} / \mathrm{mol}$. The slight difference of W-factor largely affects the activation energy only in the range less than $10^{\circ}$. On the other hand, $\mathrm{YSZ} / \mathrm{SiO}_{2}$ thin films show 130 $145 \mathrm{~kJ} / \mathrm{mol}$ above $20^{\circ}$ of $\mathrm{W}$-factor. In earlier studies, the reported apparent activation energy for YSZ bulk crystal was $81 \mathrm{~kJ} / \mathrm{mol},{ }^{23)}$ $86 \mathrm{~kJ} / \mathrm{mol}^{24)} 87 \mathrm{~kJ} / \mathrm{mol}^{25)} 106 \mathrm{~kJ} / \mathrm{mol}^{16)}$ for $10 \mathrm{~mol} \% \mathrm{Y}_{2} \mathrm{O}_{3}-$ $\mathrm{ZrO}_{2}$ (10YSZ) single crystals, and $90 \mathrm{~kJ} / \mathrm{mol}$ for single-crystallike epitaxial $10 \mathrm{YSZ}$ thin films thicker than $60 \mathrm{~nm}^{25}$ ) The activation energy of $\mathrm{YSZ} / \mathrm{SiO}_{2}$ thin films is larger than that of the reported value and that of $\mathrm{YSZ} / \mathrm{MgO}$ and $\mathrm{YSZ} / \mathrm{Al}_{2} \mathrm{O}_{3}$ films in this study. Consequently, these results demonstrate that the activation energy is affected by the $W$-factor as well as another factor.

\subsection{Morphology and composition of grain boun- daries of YSZ thin films}

The previous section presented that $\mathrm{YSZ} / \mathrm{SiO}_{2}$ thin films show higher activation energy for oxygen ion conduction predicted 
from the $\mathrm{W}$-value. In this section, morphology and composition of the columnar grain boundaries of YSZ thin films were investigated using a TEM and aberration-corrected HAADF-STEM.

Figure 6 shows cross-sectional bright field images of YSZ thin films on (a) $\mathrm{MgO}$ substrate with $W=4.2^{\circ}{ }^{21)}$ (b) $\mathrm{Al}_{2} \mathrm{O}_{3}$ substrate with $W=6.8^{\circ},{ }^{21)}$ and (c) $\mathrm{SiO}_{2}$ glass substrate with $W=38.2^{\circ}$.

(a)

(b)
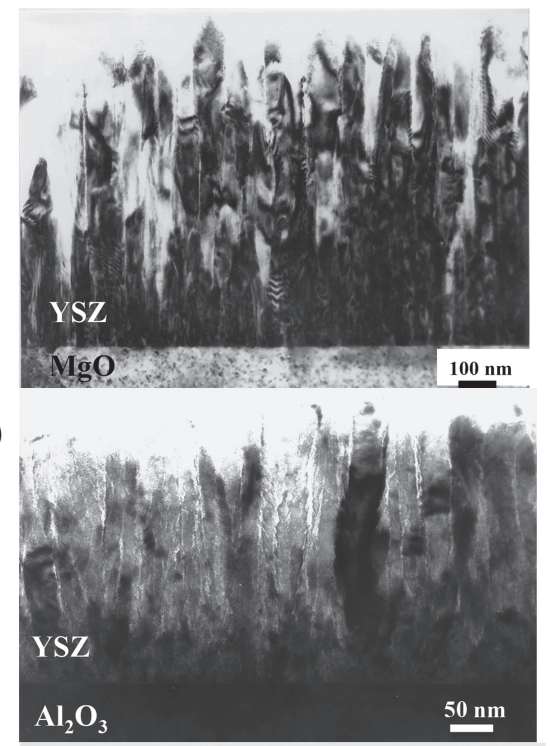

(c)

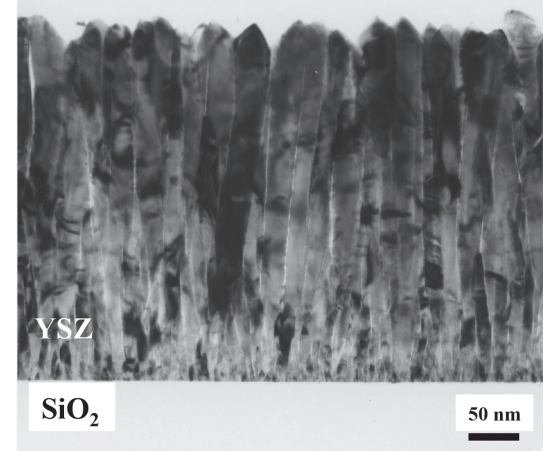

Fig. 6. Cross sectional TEM image of the columnar YSZ thin films on (a) $\mathrm{MgO}^{21)}$ (b) $\mathrm{Al}_{2} \mathrm{O}_{3},{ }^{21)}$ and (c) $\mathrm{SiO}_{2}$ substrates.
All YSZ thin films in Fig. 6 have similar columnar morphology with each grain of $20-80 \mathrm{~nm}$ width. The variation in the diffraction contrast among grains signifies that each grain might slightly rotate in the film plane. This result reflects non-zero $W$-factor of the YSZ films.

Figure 7 shows cross-sectional HRTEM images along a columnar grain boundary of the (a) $\mathrm{YSZ} / \mathrm{MgO}$ thin film with $W=4.2^{\circ}{ }^{21)}$ (b) $\mathrm{YSZ} / \mathrm{Al}_{2} \mathrm{O}_{3}$ thin film with $W=6.8^{\circ},{ }^{21)}$ and (c) $\mathrm{YSZ} / \mathrm{SiO}_{2}$ thin film with $W=38.2^{\circ}$. The $\mathrm{YSZ} / \mathrm{MgO}$ and $\mathrm{YSZ} /$ $\mathrm{Al}_{2} \mathrm{O}_{3}$ thin films show typical lattice fringes, which are observed in columnar grains as well as the columnar grain boundary. The lattice fringes with the interval of 0.26 and $0.30 \mathrm{~nm}$ respectively correspond to the $\{200\}$ and $\{111\}$ planes. These films show that (001) planes orientate the out-of-plane direction. YSZ/MgO thin films show a small angle tilt columnar grain boundary of $3^{\circ}$. Almost no dislocation occurs along the grain boundary. YSZ/ $\mathrm{Al}_{2} \mathrm{O}_{3}$ thin films also show a small angle tilt columnar grain boundary of $5^{\circ}$. Edge dislocations are arranged along the grain boundary. Thus, a $W$-factor corresponds to a correlation between rotation in the in-plane and out-of plane directions of the YSZ thin films. Details of these structures have already been elucidated in an earlier study. ${ }^{21)}$ In contrast, $\mathrm{YSZ} / \mathrm{SiO}_{2}$ thin films show a different structure along columnar grain boundaries. Some regions show amorphous-like phase contrast, which means that the second phase grows around the columnar grain boundaries.

The chemical composition presence of the second phase was investigated. Figure 8 depicts HAADF-STEM image, and STEM-EDS elemental mapping of $\mathrm{Mg}-\mathrm{K}, \mathrm{Zr}-\mathrm{K}$, and $\mathrm{Y}-\mathrm{K}$ characteristic X-rays around columnar grain boundaries in YSZ/ $\mathrm{MgO}$ thin films. The $\mathrm{O}-\mathrm{K}$ characteristic $\mathrm{X}$-ray is homogeneous. Therefore, it is omitted. The $\mathrm{Mg}, \mathrm{Zr}$, and $\mathrm{Y}$ maps show uniform contrast. Thin films are composed from Zr, Y, and O. However, $\mathrm{Mg}$ was detected uniformly from the entire area including carbon passivation coating on the YSZ film surface. The Mg map shows lower intensity than either the Zr or Y map. Therefore, the local contrast variation in the HAADF-STEM image is not attributed to the compositional difference, but is attributed to the structural difference that affects the scattering condition of the electron beam passing through the thin foils. Consequently, $\mathrm{Mg}$ detected from YSZ layer can be attributed to the re-deposition of the sputtered debris of the $\mathrm{MgO}$ substrate under the ion-milling
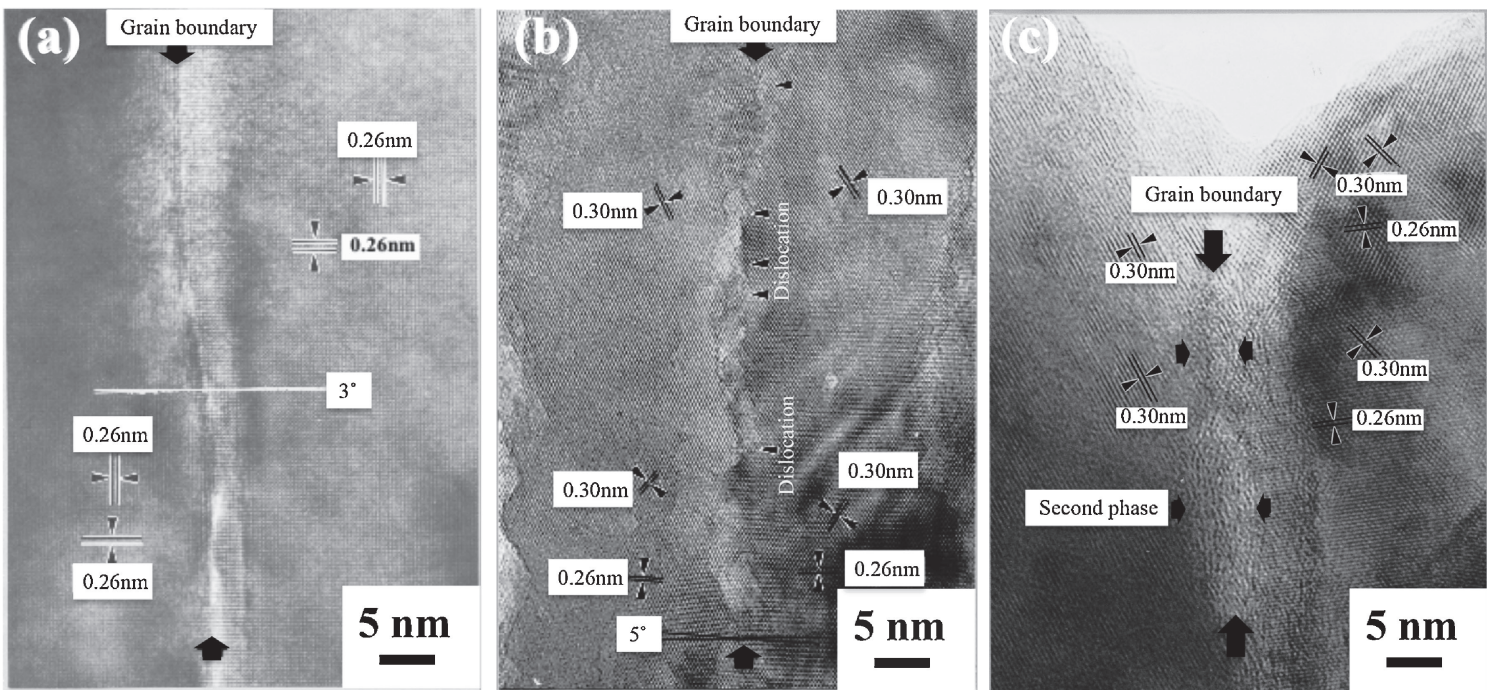

Fig. 7. Cross-sectional HRTEM image across a columnar grain boundaries in YSZ films on (a) $\mathrm{MgO},{ }^{21)}$ (b) $\mathrm{Al}_{2} \mathrm{O}_{3},{ }^{21)}$ and (c) $\mathrm{SiO}_{2}$ substrates. 
(a)

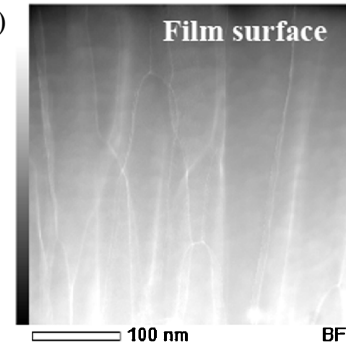

(c)

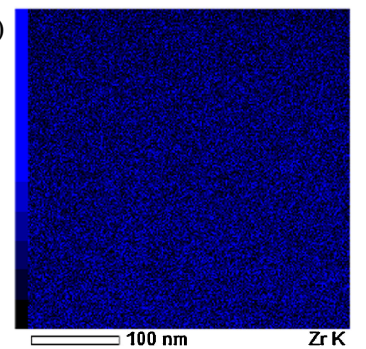

(b)

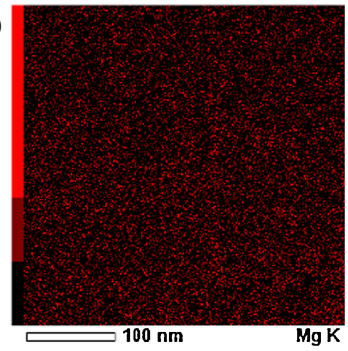

(d)

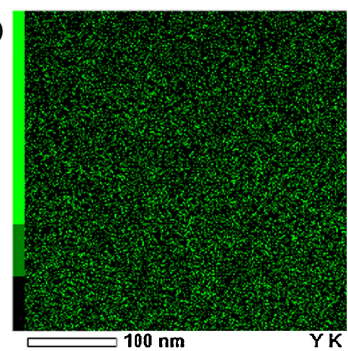

Fig. 8. (a) Cross-sectional HAADF-STEM image of YSZ/MgO thin film. (b-d) $\mathrm{Mg}-\mathrm{K}, \mathrm{Zr}-\mathrm{K}$, and $\mathrm{Y}-\mathrm{K}$ elemental maps of (a), respectively.

(a)

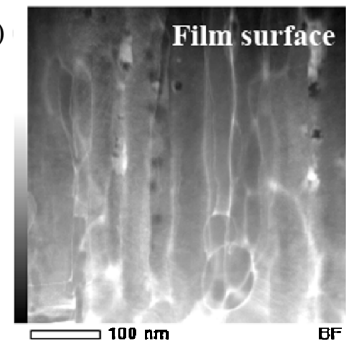

(c)

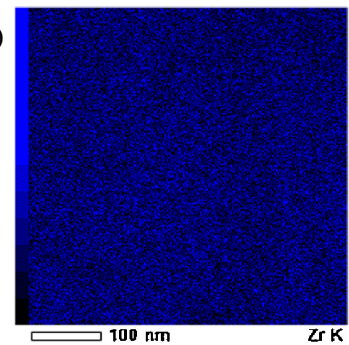

(b)

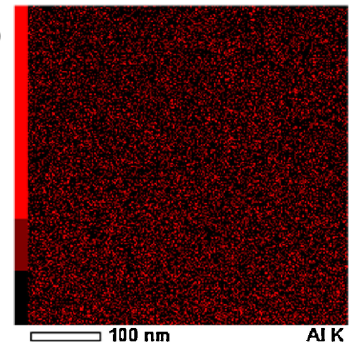

(d)

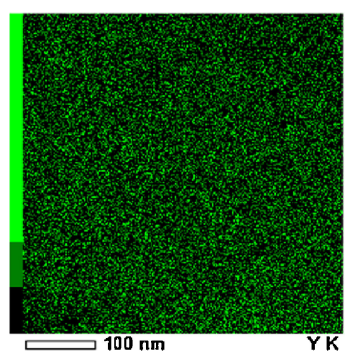

Fig. 9. (a) Cross-sectional HAADF-STEM image of $\mathrm{YSZ} / \mathrm{Al}_{2} \mathrm{O}_{3}$ thin film. (b-d) Al-K, $\mathrm{Zr}-\mathrm{K}$, and $\mathrm{Y}-\mathrm{K}$ elemental maps of (a), respectively.

\section{process}

Figure 9 depicts HAADF-STEM image, and STEM-EDS elemental mapping of $\mathrm{Al}-\mathrm{K}, \mathrm{Zr}-\mathrm{K}$, and $\mathrm{Y}-\mathrm{K}$ characteristic $\mathrm{X}$-ray around columnar grain boundaries in $\mathrm{YSZ} / \mathrm{Al}_{2} \mathrm{O}_{3}$ thin films. The $\mathrm{O}-\mathrm{K}$ characteristic $\mathrm{X}$-ray is omitted. The HAADF-STEM image shows dark or bright contrast locally. The Al, Zr, and Y maps show uniform contrast. The Al map shows lower intensity than either the $\mathrm{Zr}$ or $\mathrm{Y}$ map. Then, the local contrast variation in the HAADF-STEM image is not attributed to the compositional difference, but is attributed to the structural difference that affects the scattering condition of the electron beam passing through the thin foils, which means that Al detected from the YSZ layer is attributable to the re-deposition of the sputtered debris of the $\mathrm{Al}_{2} \mathrm{O}_{3}$ substrate under the ion-milling process.

Figure 10 depicts HAADF-STEM image, and STEM-EDS elemental mapping of $\mathrm{Si}-\mathrm{K}, \mathrm{Zr}-\mathrm{K}$, and $\mathrm{Y}-\mathrm{K}$ characteristic $\mathrm{X}$ -

(a)

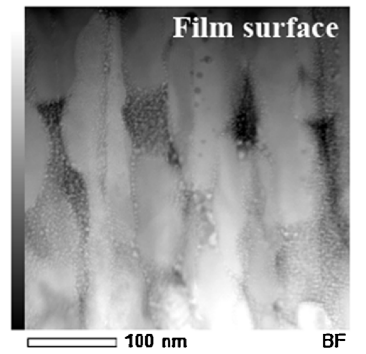

(c)

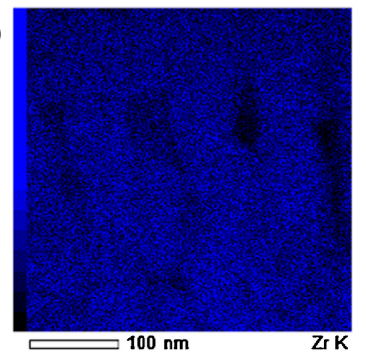

(b)

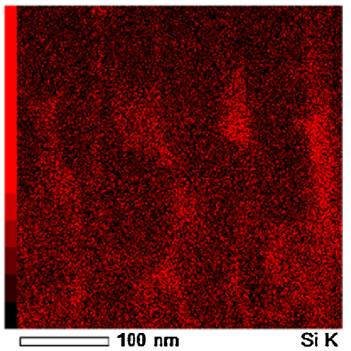

(d)

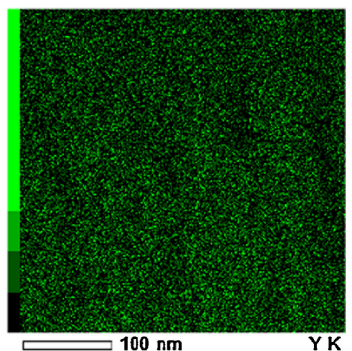

Fig. 10. (a) Cross-sectional HAADF-STEM image of $\mathrm{YSZ} / \mathrm{SiO}_{2}$ thin film. (b-d) Si-K, Zr-K, and Y-K elemental maps of (a), respectively.

rays around columnar grain boundaries in $\mathrm{YSZ} / \mathrm{SiO}_{2}$ thin films. The $\mathrm{O}-\mathrm{K}$ characteristic X-ray is omitted. The HAADF-STEM image shows large mid-gaps between columnar grains, and nanoparticle-like contrast of less than $10 \mathrm{~nm}$ in diameter. Figures 10(a) and 10(b) clearly present that these nanoparticles appear preferentially at the grain boundary and the large midgaps, where $\mathrm{Si}$ concentration increases and $\mathrm{Zr}$ and $\mathrm{Y}$ concentration decreases. The $\mathrm{Si}$ map shows comparable intensity to those of $\mathrm{Zr}$ and $\mathrm{Y}$ maps. This feature differs from the $\mathrm{Mg}$ and the Al maps shown in Figs. 8 and 9. Figure 7(c) shows that amorphous phase exists between YSZ columnar grains. The composition at the Si rich region is $\mathrm{Si}: \mathrm{Zr}: \mathrm{Y}=25: 65: 10$ (at. \%) by the point analysis of STEM-EDS analysis. The Zr:Y ratio is $87: 13$ (at.\%), which engenders the composition of 6.5 mol $\% \mathrm{Y}_{2} \mathrm{O}_{3}$ doped $\mathrm{ZrO}_{2}$. This composition agrees well with the average composition by EDX, 6 mol $\% \mathrm{Y}_{2} \mathrm{O}_{3}$ doped $\mathrm{ZrO}_{2}$. Then, the detected $\mathrm{Si}$ can be regarded as $\mathrm{SiO}_{2}$ glass phase. These results show that the $\mathrm{SiO}_{2}$ glass phase locally precipitates along the columnar grain boundary in YSZ. The unique source of $\mathrm{SiO}_{2}$ glass phase would come from the substrate in the film deposition process. Trace $\mathrm{Si}$ on the YSZ columnar grains is the re-deposition of the sputtered debris of the $\mathrm{SiO}_{2}$ glass substrate under the ionmilling process. Then, Fig. 10 shows that the local contrast variation in the HAADF-STEM image is attributable mainly to the compositional difference between the grain interior and the grain boundaries.

\section{Discussion}

The results obtained in this study indicate that the coherence of the columnar grain boundary as well as the second phase of $\mathrm{SiO}_{2}$ affects differently the ionic conductivity of YSZ thin films with columnar morphology. We have already discussed conduction mechanisms in a previous paper, which described the grain boundary conduction limit of the in-plane ionic conductivity of the columnar thin films, and explained that the in-plane conduction path is expected to be bulk-grain boundary-bulk type. ${ }^{21)}$ This section explains the conduction mechanism of the films from the viewpoint of the second phase at the grain boundary.

Generally, grain boundaries constitute barriers to oxygen ion 
migration. The activation energy shows the barriers to the oxygen ion conductivity. Our results indicate clearly that two factors are important to investigate the activation energy: the $W$-factor and second phase at columnar grain boundaries. The $W$-factor is pronounced for the chemically clean grain boundary. It is a structural effect on the ionic conductivity of YSZ. Dislocations and mid-gaps between columnar grains disrupt the coherence and continuity of the crystalline lattice. These structural defects increase the apparent activation energy of the ionic conductivity. The apparent activation energy of the ionic conductivity of YSZ/ $\mathrm{MgO}$ and $\mathrm{YSZ} / \mathrm{Al}_{2} \mathrm{O}_{3}$ thin films can be understood simply by the $W$-factor, which includes the tilt angle and rotation angle.

Results of STEM-EDS analysis clearly indicate that the second phase of $\mathrm{SiO}_{2}$ glass phase was observed along the columnar grain boundaries in $\mathrm{YSZ} / \mathrm{SiO}_{2}$ thin films. $\mathrm{SiO}_{2}$ glass is a typical insulator as an oxygen ionic conductor. It blocks the oxygen ion conduction. The $\mathrm{SiO}_{2}$ glass phase among columnar grains as well as the higher $W$-factor of $\mathrm{YSZ} / \mathrm{SiO}_{2}$ thin films reflects the atomic structure at the columnar grain boundaries. Therefore, $\mathrm{YSZ} / \mathrm{SiO}_{2}$ thin films shows lower ionic conductivity and higher apparent activation energy than $\mathrm{YSZ} / \mathrm{MgO}$ or $\mathrm{YSZ} / \mathrm{Al}_{2} \mathrm{O}_{3}$ thin films by $20-25 \mathrm{~kJ} / \mathrm{mol}$. Consequently, the coherence as well as the chemical cleanliness of the columnar grain boundary are critical factors for the ionic conductivity of YSZ thin films with columnar morphology.

\section{Conclusion}

This study elucidated the effects of the structural coherence as well as the effects of chemical cleanliness on the ionic conductivity at the columnar grain boundary of $6 \mathrm{~mol} \% \mathrm{Y}_{2} \mathrm{O}_{3}$ doped $\mathrm{ZrO}_{2}$ (6YSZ) thin films prepared using MOCVD. This study yielded the following conclusions.

(1) YSZ thin films deposited on $\mathrm{MgO}(100), \mathrm{Al}_{2} \mathrm{O}_{3}(102)$, and $\mathrm{SiO}_{2}$ glass substrates have columnar morphologies.

(2) Structural coherence of columnar grain boundary was estimated quantitatively using the $W$-factor, as calculated from the pole figure.

(3) The columnar grain boundary is atomically sharp for $\mathrm{YSZ} / \mathrm{MgO}$ and $\mathrm{YSZ} / \mathrm{Al}_{2} \mathrm{O}_{3}$, with no second phase. However, $\mathrm{SiO}_{2}$ glass phase is formed along the columnar grain boundaries of $\mathrm{YSZ} / \mathrm{SiO}_{2}$ thin films.

(4) Impedance measurement revealed that the total ionic conductivity of the thin films was restricted by the columnar grain boundary. The ionic conductivity and the apparent activation energy are restricted by two factors: the structural coherence and the chemical cleanliness along the columnar grain boundaries.

Acknowledgements This work is partially supported by JSPS KAKENHI Grant Numbers 24656372, 11750584, The Mikiya
Science and Technology Foundation, and The Iwatani Naoji Foundation, Tonen General Sekiyu Research \& Development Encouragement \& Assistance Foundation and The Noguchi Institute. A part of TEM analysis was supported by JEOL Ltd. A part of HAADF-STEM analysis was supported by Dr. Kosei Kobayashi of Graduate School of Engineering, Tohoku University.

\section{References}

1) K. Yardley, Mineral. Mag., 2, 169-179 (1928).

2) O. Ruff and F. Ebert, Z. Anorg. Chem., 180, 19-41 (1929).

3) G. Teufer, Acta Crystallogr., 15, 1187 (1962).

4) W. W. Barker, F. P. Baily and W. Garrett, J. Solid State Chem., 7, 448-453 (1973).

5) D. K. Smith and C. F. Cline, J. Am. Ceram. Soc., 45, 249-250 (1962).

6) E. C. Subbarao, H. S. Maiti and K. K. Srivastava, Phys. Status Solidi A, 21, 9-40 (1975).

7) H. G. Scott, J. Mater. Sci., 10, 1527-1535 (1975).

8) C. F. Grain, J. Am. Ceram. Soc., 50, 288-296 (1967).

9) T. Kiguchi, A. Saiki, K. Shinozaki, K. Teryama and N. Mizutani, J. Ceram. Soc. Japan, 105, 775-778 (1997).

10) M. Kleitz, H. Bernard, E. Frenandez, and E. Schouler, Advances in Ceramics Vol.3, Ed. by H. A Heuer and L. W. Hobbs, The Am. Ceram. Soc. Columbus, Ohio (1981) pp. 310-336.

11) S. Ikeda, O. Sakurai, K. Uematsu, N. Mizutani and K. Kato, J. Mater. Sci., 20, 4593-4600 (1985).

12) D. W. Striker and W. G. Carison, J. Am. Ceram. Soc., 47, 122 127 (1964).

13) S. P. S. Badwal, J. Mater. Sci., 19, 1767-1776 (1984).

14) B. C. H. Steele, Solid State Ionics, 75, 157-165 (1995).

15) M. Aoki, Y.-M. Chiang, I. Kosacki, L. J.-R. Lee, H. Tuller and Y. Liu, J. Am. Ceram. Soc., 79, 1169-1180 (1996).

16) I. Kosacki, T. Suzuki, V. Petrosky and H. U. Anderson, Solid State Ionics, 136-137, 1225-1233 (2000).

17) Y. Ikuhara, P. Thavorniti and T. Sakuma, Acta Mater., 45, 5275-5284 (1997).

18) Y. Ikuhara, I. Tanaka, P. Thavorniti and T. Sakuma, J. Electron Microsc. (Tokyo), 46, 467-472 (1997).

19) I. Kosacki, C. M. Rouleau, P. F. Becher, J. Bentley and D. H. Lowndes, Solid State Ionics, 176, 1319-1326 (2005).

20) K. L. Merkle, G.-R. Bai, Z. Li, C.-Y. Song and L. J. Thompson, Phys. Status Solidi A, 166, 73-89 (1998).

21) T. Kiguchi, T. J. Konno, H. Funakubo, O. Sakurai and K. Shinozaki, J. Ceram. Soc. Japan, 122, 72-77 (2014).

22) T. Matsuzaki, N. Okuda, K. Shinozaki, N. Mizutani and H. Funakubo, Jpn. J. Appl. Phys., 37, 6229-6232 (1998).

23) P. S. Manning, J. D. Sirman, R. A. De Souza and J. A. Kliner, Solid State Ionics, 100, 1-10 (1997).

24) K. Otsuka, K. Matsunaga, A. Nakamura, S. Ii, A. Kuwabara, T. Yamamoto and Y. Ikuhara, Mater. Trans., 45, 2042-2045 (2004).

25) M. Filal, C. Petot, M. Mokchah, C. Chateau and J. L. Carpentier, Solid State Ionics, 80, 27-35 (1995). 